\title{
Season-Related Differences in the Biosynthetic Activity of the Neonatal Chicken Pineal Gland
}

\author{
Aneta Piesiewicz*, Podobas Ewa, Kędzierska Urszula, Joachimiak Ewa, Markowska Magdalena, \\ Majewski Pawel and Skwarlo-Sonta Krystyna
}

Department of Animal Physiology, Faculty of Biology, University of Warsaw, Poland

\begin{abstract}
Influence of the season of hatch on the functional characteristics of the pineal gland was examined in neonatal Hi-Line male chickens. The pineal glands from 2-day-old birds hatched in summer and winter, and kept from the day of hatch in artificial lighting conditions (12L:12D), were isolated under dim red light in the middle of the day or night. The pineal glands were analyzed to characterize their melatonin biosynthetic activity: (1) expression of the Arylalkylamine$\mathrm{N}$-acetyltransferase and Hydroxyindole-O-methyltransferase genes, encoding the final two enzymes of the melatonin biosynthesis pathway; (2) the activity of AA-NAT and HIOMT; and (3) the content of the main substrates of this pathway, tryptophan (TRY) and serotonin (5-HT). Daily changes in pineal AA-NAT activity were observed in chickens hatched in both seasons, with a more pronounced nocturnal increase in summer. In contrast, the level of Aa-nat gene expression, although exhibited the same nocturnal/diurnal pattern in both seasons, was much lower in the summer. The activity of HIOMT was season- and daytime-independent. In "winter" chickens the pineal content of 5-HT was low and stable, while in "summer" birds it was correlated with levels of AA-NAT activity and Aa-nat gene expression. TRY content was very high and exhibited neither daily nor seasonal changes. The pineal gland of newly hatched chickens kept in controlled 12L:12D conditions exhibits daily variations in melatonin biosynthetic activity influenced by the season. This suggests a maternal effect on the perinatal/postnatal development of the circadian clock residing in the chicken pineal gland.
\end{abstract}

Keywords: Melatonin biosynthesis pathway, neonatal chicken, pineal gland, seasonal changes.

\section{INTRODUCTION}

The majority of physiological processes are subject to cyclical changes, the most important being related to daily variations between day and night, and the annual succession of the seasons. In temperate latitudes, photoperiod appears to be the most reliable parameter and, as such, is used by animals to gauge the time of day/year in order to synchronize daily and seasonal rhythms of physiology and behaviour to environmental changes [1-3].

Circadian rhythms are generated by an endogenous pacemaker (the "circadian clock") and are synchronized with environmental lighting conditions. In birds, the circadian clock system consists of three functionally equal structures: one is located in the visual suprachiasmatic nuclei (avian brain structures equivalent to the mammalian $\mathrm{SCN}$ ), another in the pineal gland itself and the third, which controls local melatonin production, in the retina [4].

The photic input reaches the avian pineal gland via two pathways: indirectly, from the eyes through the retinohypothalamic tract, SCN and sympathetic innervations, and directly through the photosensitive pineal cells [5-7]. Within the cells of the pineal gland (pinealocytes), environmental photoperiodic information is converted into a neuroendo-

*Address correspondence to this author at the Department of Animal Physiology, Faculty of Biology, University of Warsaw, Miecznikowa 1, 02096 Warsaw, Poland; Tel: +48 225541 025; Fax: +48 225541 030; E-mail: apiesiewicz@biol.uw.edu.pl crine signal, i.e. the methoxyindole hormone melatonin, secreted during the dark phase of the light/dark (LD) cycle and often called the "hormone of darkness" [8].

The molecular mechanisms of melatonin biosynthesis within pinealocytes have been thoroughly established (Fig. 1) [9]. The amino acid tryptophan is taken up from the blood and converted to 5-hydroxytryptophan (5-HTP) by tryptophan hydroxylase (TrH; E.C. 1.14.16.4). Then, aromatic amino acid decarboxylase (AADC; E.C.4.1.1.28) converts 5HTP to serotonin (5-HT). During the night, 5-HT is acetylated to $\mathrm{N}$-acetylserotonin (NAS) by arylalkylamine-Nacetyltransferase (AA-NAT; E.C. 2.3.1.87), and thereafter hydroxyindole-O-methyltransferase (HIOMT; E.C.2.1.1.4) converts NAS to melatonin [10]. The hormone is not stored in the pinealocytes but is immediately released into the capillary vessel and peripheral circulation. Therefore, the pineal content and circulating levels of melatonin are highly correlated [11].

The avian pineal gland acquires its oscillatory function during embryogenesis. Melatonin is initially detected in the chicken embryo on the 10th day of embryonic life (ED10) [12], while a daily rhythm of melatonin may be demonstrated in vivo in the pineal gland of 18- and 20-day-old embryos, with increasing amplitude from ED19 [13] until postembryonic day 21 (3 weeks after hatch) [13, 14]. Melatonin release by cultured pineal cells from 13- and 14day-old chicken embryos held under a $12 \mathrm{~h}$ light:12 h dark cycle increases during the dark phase and decreases during the light phase. A circadian rhythm of melatonin release is 


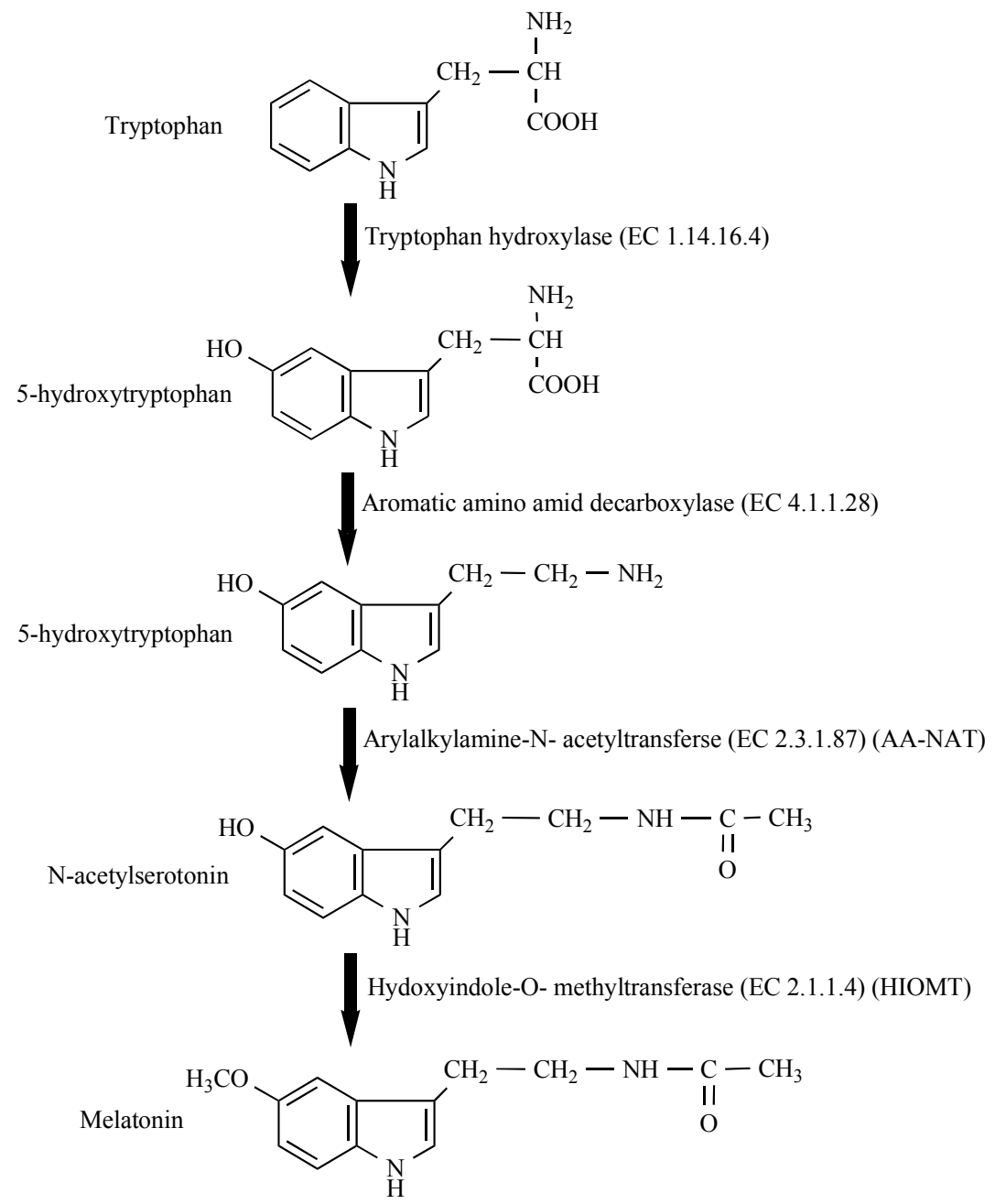

Fig. (1). Melatonin biosynthesis pathway.

observed in pineal cells isolated from 18-day-old chicken embryos and cultured under constant darkness (DD) conditions [15]. These data indicate that the pineal melatonin synthesizing machinery is not only present in the chicken embryo, but is already synchronized to the environment [16]. Unfortunately, in the aforementioned reports there is no indication of the season in which the eggs were incubated. Our previous studies have demonstrated that in 3-week-old Hi-line male chickens kept from hatch under controlled artificial lighting conditions (L:D 12:12) the daily rhythm of pineal AA-NAT activity changes according to the local season [17]. To determine whether the season-related pattern of the daily rhythm of chicken pineal AA-NAT activity is already established during embryonic development or whether it is a postembryonic event, we examined the circadian rhythm of pineal AA-NAT activity in 2-, 9- and 16-day-old chickens hatched in both winter and summer and kept from the day of hatch under the same artificial photoperiod - L:D 12:12 [18]. The results of this study identified a kind of postembryonic maturation of the pineal AA-NAT circadian rhythm seen only in chickens hatched in winter; the nocturnal peak of AA-NAT was lowest in the youngest birds examined and it increased with age. In contrast, in 2-day-old chicks hatched in summer, the pattern of pineal AA-NAT activity was comparable with that previously observed in 3 -week-old birds. These findings indicate that one or more steps of the pineal melatonin biosynthesis pathway are season-dependent in neonatal chickens. The present study was undertaken to examine the influence of the season of hatch on pineal melatonin biosynthesis (substrate availability, gene expression and enzyme activity) in 2-day-old male Hi-line chickens, kept from hatch under artificial L:D 12:12 lighting conditions.

\section{MATERIALS AND METHODS}

\section{Animals}

Experiments were performed on neonatal (2-day-old) male Hi-Line chickens hatched in the season of shortest days (winter, January) and longest days (summer, June). The eggs were purchased from the laying hens kept at commercial farm (fully controlled lightproof house) in controlled lighting conditions (16h light: $8 \mathrm{~h}$ darkness) with free access to food and water. The mother's food was adjusted to the period of theirs development and was the same, regardless of the season. Incubated eggs were obtained from the same henmothers being, therefore, in summer period older by a half of 
year than those in winter. The eggs at hatchery were incubated in constant darkness at the appropriate temperature. On the day of hatch, the chicks were transported from the hatchery to the animal facility of the Faculty of Biology, Warsaw University (fully isolated from the environmental conditions) and reared under controlled light (12 h light:12 h darkness, lights on at 04:00) and temperature conditions (32 $\pm 2^{\circ} \mathrm{C}$ ), with free access to the water and the same standard food regardless of season.

Two-day-old chicks were sacrificed by decapitation in the middle of the day (ZT6) and in the middle of the night (ZT18): 9 individuals were killed at each time point. Their pineal glands were isolated under dim red light, immediately frozen in liquid nitrogen and stored at $-75^{\circ} \mathrm{C}$ prior to further analysis. All treatments were approved by the Local Ethical Commission and were in accordance with Polish regulations concerning experiments on animals.

\section{AA-NAT and HIOMT Activity Measurement}

The activity of both enzymes was measured using the liquid biphasic diffusion method [19] modified by Majewski et al. [20]. Briefly, individual pineal glands were disrupted by sonication in $100 \mu \mathrm{l}$ of ice-cold $0.05 \mathrm{M}$ sodium phosphate buffer (16 mM Na $\mathrm{HPO}_{4}, 40 \mathrm{mM} \mathrm{NaH} \mathrm{PO}_{4}, \mathrm{pH}$ 6.8). Aliquots of $10 \mu \mathrm{l}$ of the sonicate were added to reaction mixtures containing $1.5 \mathrm{mM}$ tryptamine- $\mathrm{HCl}, 0.1 \mathrm{mM}$ acetyl coenzyme A and $0.01 \mathrm{mM}$ of ${ }^{3}[\mathrm{H}]$-acetyl coenzyme A $(0.2 \mu \mathrm{Ci}$ /assay) for the AA-NAT assay, and $0.25 \mathrm{mM} \mathrm{N}$ acetylserotonin and $0.125 \mathrm{mM} \mathrm{1:1}$ mixture of S-adenosylmethionine with ${ }^{3}[\mathrm{H}]-\mathrm{S}$-adenosyl-methionine $(492.1 \mathrm{GBq} /$ mmol), for HIOMT activity measurement. Reactions prepared in triplicate were incubated at $37^{\circ} \mathrm{C}$ for $20 \mathrm{~min}$. and then stopped by the addition of $180 \mu 1$ of ice-cold sodium phosphate buffer $(50 \mathrm{mM}, \mathrm{pH} 6.8)$. The diluted reaction mixtures were rapidly transferred to vials containing $3 \mathrm{ml}$ of scintillation fluid [18 mM 2,5-diphenyloxazole (PPO), 0.27 $\mathrm{mM}$ 1,4-Bis(5-phenyl-2-oxazolyl)benzene (POPOP) in toluene]. After $24 \mathrm{~h}$ incubation at room temperature the levels of $\mathrm{N}^{3}[\mathrm{H}]$-acetyltryptamine for the AA-NAT assay or newly synthesized ${ }^{3}[\mathrm{H}]$-melatonin for the HIOMT assay were determined using a liquid scintillation counter (Beckman Instruments). The activity of both enzymes was expressed as nmol of the product formed/pineal gland $/ \mathrm{h}$.

\section{Measurement of Pineal Serotonin and L-Tryptophan Levels}

Pineal glands were sonicated in $25 \mu 1$ of ice-cold sodium phosphate buffer (50 mM, pH 6.8) and aliquots of 2.5 and 10 $\mu \mathrm{l}$ were used to measure the serotonin and L-tryptophan concentration, respectively. Serotonin was measured using a competitive ELISA assay kit (IBL). Duplicate samples of the pineal sonicate were diluted 8 times with Assay Buffer and processed according to the manufacturer's protocol. The serotonin concentration was quantified by spectrophotometry (Victor, Perkin Elmer) at $405 \mathrm{~nm}$ within $20 \mathrm{~min}$. of adding the Stop Solution. The serotonin level was expressed as $\mathrm{pmol} / \mathrm{pineal}$ gland. L-tryptophan was measured in duplicate pineal sonicate samples using a Bridge-It L-Tryptophan Fluorescence Assay Kit (Mediomics), according to the manufacturer's protocol. The L-tryptophan concentration was quantified using a microplate reader fluorometer
(Ascent, Labsystems) with appropriate settings: excitation $485 \mathrm{~nm}$; emission $665 \mathrm{~nm}$. The L-tryptophan level was expressed as $\mathrm{pmol} / \mathrm{pineal}$ gland.

\section{Pineal Gene (Aa-nat and Hiomt) Expression Analysis}

Total RNA was isolated from each pineal gland using a GF-1 Total RNA Extraction Kit (Vivantis). Reverse transcription of $650 \mathrm{ng}$ total RNA was performed in each pineal gland ( 3 pineal glands per time point) reactions containing $\mathrm{M}-\mathrm{MuLV}$ reverse transcriptase $(200 \mathrm{U}$, Finnzymes), transcriptase reaction buffer (Finnzymes), 0.5 mM dNTPs (New England Biolabs), 4.6 mM oligo dT (New England Biolabs) and RNasin RNase inhibitor N211A (20 U, New England Biolabs), incubated, $2 \mathrm{~h}, 42^{\circ} \mathrm{C}$ in a DNAengine thermocycler (Bio-Rad). Fragments of the Aa-nat, Hiomt and Tbp (TATA-binding protein, housekeeping gene) cDNAs were amplified by PCR using the same primers described below, gel purified and cloned in the pCR II-TOPO cloning vector (Invitrogen). These cDNA fragments were used as quantification standards for qRT-PCR.

In separate real-time RT-PCR assays, cDNA fragments were amplified from each sample using the following primer sets: Aa-nat (GenBank accession U46502) forward: 5'-TGT CAGAGCTGCCCCAGATAAG, and reverse: 5'- AGATGA AGGCTTCCCTCTCGAT (efficiency $\mathrm{E}=1.895$ and sensitivity $10^{2}-10^{7}$ ); Hiomt (GenBank X62309) forward: 5'ATTCAATCCCTGAAGCTGACCTC and reverse 5'-TCTT CACTCAGGAGCGATTCAAC (efficiency $\mathrm{E}=1.936$ and sensitivity $10^{2}-10^{7}$ ); Tbp (GenBank D83135) forward: 5'CAGACTCTTACCACAGCCCCT and reverse 5'- TCTT CACTCAGGAGCGATTCAAC (efficiency $\mathrm{E}=1.908$ and sensitivity $\left.10^{2}-10^{7}\right)$. Reactions contained cDNA $(10 \%$ of RT reaction volume), SYBR green I, PCR master mix containing polymerase (F-410L DyNAmo ${ }^{\mathrm{TM}}$ qPCR Kit F-410S/L, Finnzymes) and $0.5 \mathrm{mM}$ each gene-specific primer. The reactions were carried out in a Quantica thermocycler (Techne) under the following cycling conditions: $95^{\circ} \mathrm{C}$ for $10 \mathrm{~min}$, followed by 55 cycles of $94^{\circ} \mathrm{C}$ for $20 \mathrm{~s}, 63^{\circ} \mathrm{C}$ for 20 $\mathrm{s}$ and $72^{\circ} \mathrm{C}$ for $20 \mathrm{~s}$. Transcript level quantification was performed by Quantica software. Each sample was assayed in duplicate (in total six results for each time point). Results from each time poit and season were averaged and normalized to the mean $T b p$ level.

\section{Statistical Analysis}

Statistical significance was determined by the Student's $t$ test. Data are expressed as means \pm S.E.

\section{RESULTS}

Aa-nat gene expression in the pineal glands of both seasonal chicken groups was found to be higher in the middle of the dark phase than in the light phase, and this difference was statistically significant in chickens hatched both in winter and in summer $(\mathrm{p}<0.01)$. Moreover, the level of Aa-nat mRNA was much higher in "winter" than in "summer" chicks, particularly in the light period (ZT6, $\mathrm{p}<0.001$ ) (Fig. 2A).

In contrast, pineal expression of the Hiomt gene exhibited a significant $(\mathrm{p}<0.001)$ diurnal-nocturnal difference (with 

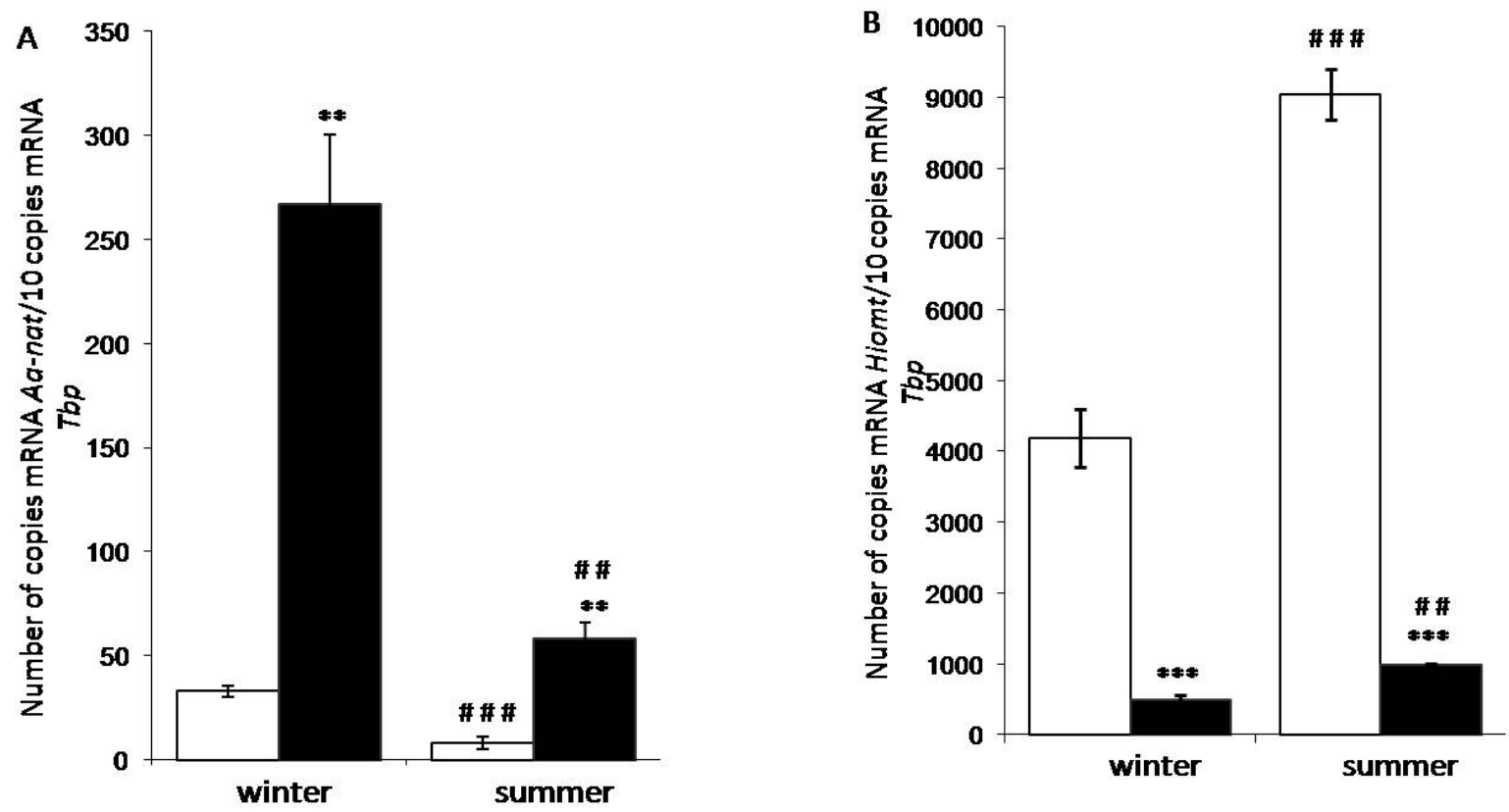

Fig. (2). Pineal Aa-nat (A) and Hiomt (B) gene expression in the middle of the light phase (ZT6, white bars) and in the middle of the dark phase (ZT18, black bars) in chickens hatched in the winter and summer, quantified by qRT-PCR. Results are given as the mean ( \pm S.E.) for 3 pineal glands per group, measured in duplicate and normalized to the expression of the housekeeping gene Tbp. Asterisks $(*)$ indicate a significant difference between ZT6 and ZT18 ( $\square$ vs. .) with following levels of significance $* \mathrm{P} \leq 0.05,{ }^{*} * \mathrm{P} \leq 0.01, * * * \mathrm{P} \leq 0.001$. The hash sign (\#) indicates a significant difference between winter and summer for the same ZT ( $v$ vs. $\mathbf{\square} ; \square v s . \square)$ with following levels of significance $\# \mathrm{P} \leq 0.05, \# \# \mathrm{P} \leq 0.01, \# \# \# \mathrm{P} \leq 0.001$.
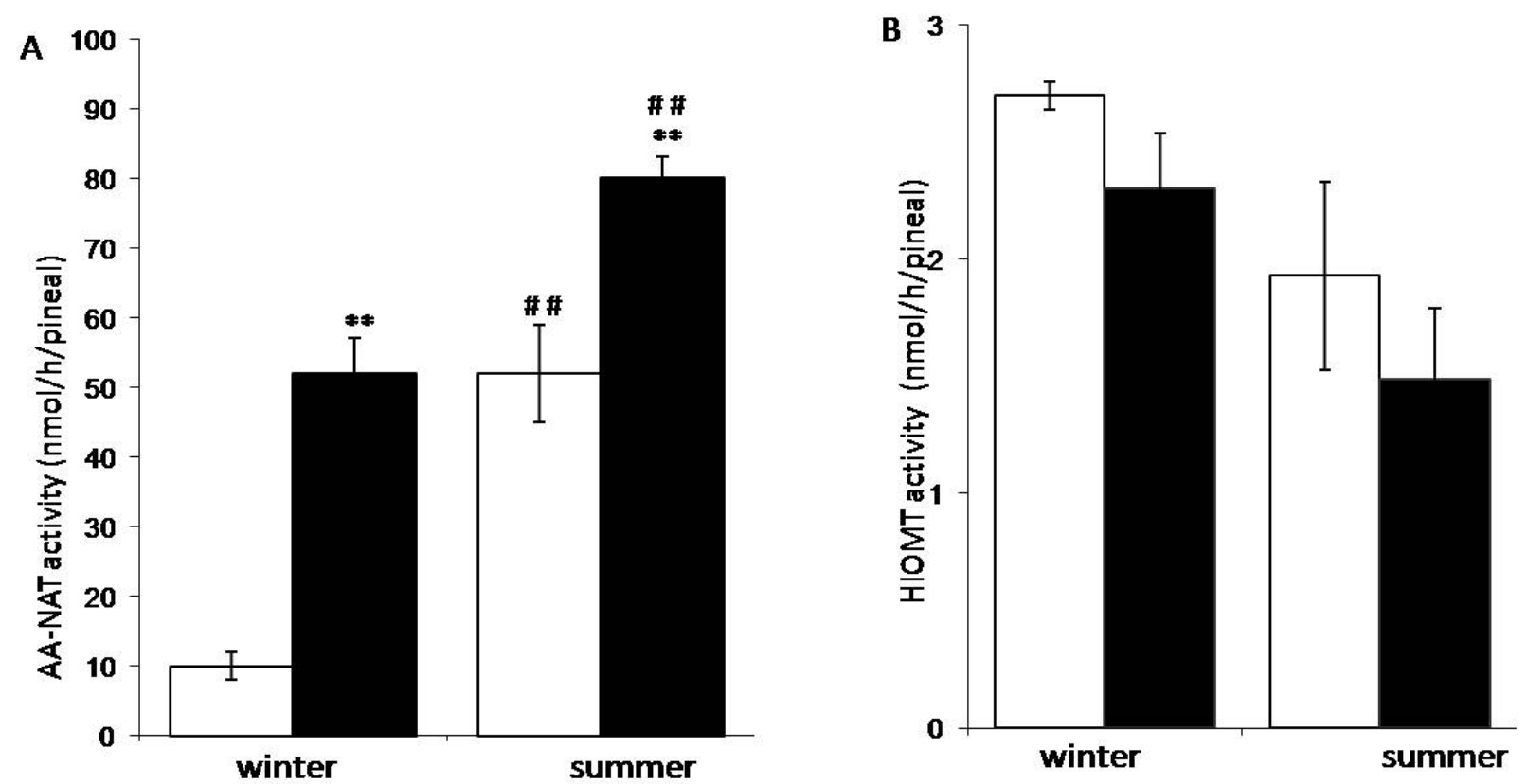

Fig. (3). Pineal AA-NAT (A) and HIOMT (B) activity measured in the middle of the light phase (ZT6, white bars) and in the middle of the dark phase (ZT18, black bars) in chickens hatched in winter and in summer. Other features as in Fig. (2).

elevated transcript level during the light phase) in the chickens from both seasons. Furthermore, the quantity of Hiomt mRNA was much higher in "summer" than in "winter" chicks, especially in the light phase $(Z T 6, \mathrm{p}<0.001)$ (Fig. 2B). In addition, the number of copies of the Hiomt transcript was several times higher than that of Aa-nat.
The pineal AA-NAT activity of "winter" and "summer" chickens exhibited a significant $(\mathrm{p}<0.01)$ nocturnal-diurnal difference, and was generally much higher in the second group (Fig. 3A). On the other hand, pineal HIOMT activity differed neither diurnally nor seasonally, but had a tendency to be higher in the "winter" birds (Fig. 3B). 

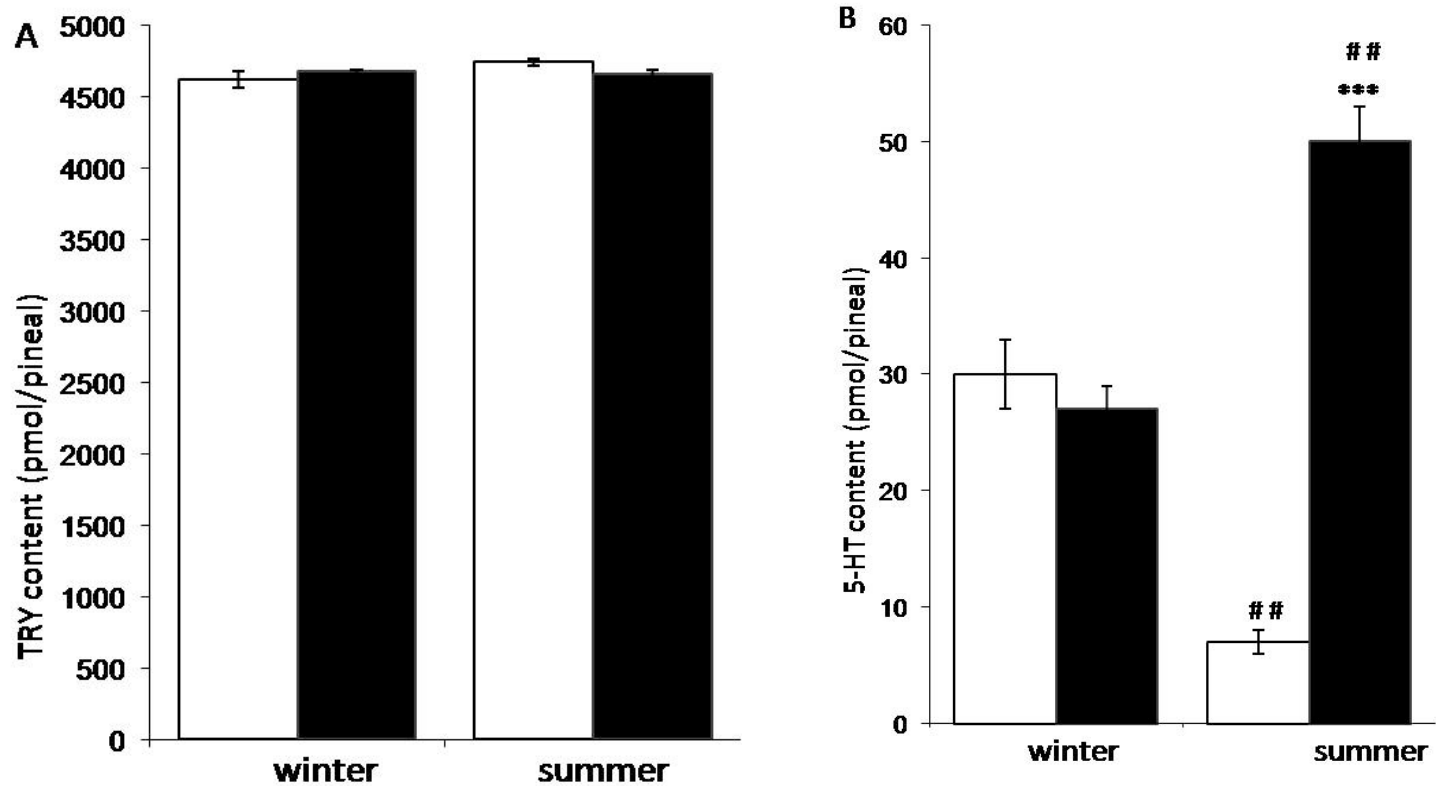

Fig. (4). Pineal tryptophan (A) and serotonin (B) content in the middle of the light phase (ZT6, white bars) and in the middle of the dark phase (ZT18, black bars) in chickens hatched in winter and in summer. Other features as in Fig. (2).

The pineal content of tryptophan, the first substrate in the melatonin biosynthetic pathway, was very high and remained constant regardless of the season or the time of measurement (Fig. 4A). The diurnal-nocturnal serotonin content was stable in the pineal glands of "winter" chickens, while in those hatched in summer it changed significantly $(p<0.001)$, with higher levels present in the middle of the dark phase (Fig. 4B). The level of serotonin differed seasonally, with significantly $(\mathrm{p}<0.01)$ higher levels at ZT18 and significantly $(\mathrm{p}<0.01)$ lower levels at ZT6 in chicks hatched in summer compared with those hatched in winter.

\section{DISCUSSION}

Previously, we demonstrated season-related differences in the shape of the curve describing nocturnal AA-NAT activity in the pineal glands of 3-week-old male chickens kept in controlled lighting conditions (L:D 12:12) [17]. Subsequent studies confirmed this observation and indicated that this seasonality is also age-dependent, because the nocturnal peak of AA-NAT activity in 2-day-old chickens kept in the same conditions was much lower in winter than in summer [18]. The present study was undertaken to determine, which step of pineal melatonin biosynthesis in 2day-old chickens is influenced by the season of hatch. For this purpose, the expression of genes encoding AA-NAT and HIOMT, the activity of these enzymes and the content of the main substrates, tryptophan (TRY) and serotonin (5-HT), were examined in pineal glands isolated in the middle of the light and dark phases from chicks kept under the artificial photoperiod L:D 12:12.

Elevated nocturnal levels of Aa-nat mRNA were found in birds hatched in both seasons, with significantly higher expression in winter than in summer (Fig. 2A). In contrast, the activity of AA-NAT was much lower in winter than in summer, although exhibited the same nocturnal/diurnal pattern in both seasons (Fig. 3A). This implies the involvement of some factor(s) that contribute to the lack of straight correlation between the amount of Aa-nat transcript and AANAT enzymatic activity observed in the pineal gland of chickens hatched in both seasons. Besides possible posttranscriptional mechanisms, the AA-NAT protein may be modified to produce a less/more active form or its enzymatic activity may be modulated by some unidentified negative/ positive regulatory factor(s) [21]. These results also suggest the existence of season-dependent regulation of AA-NAT activity and/or protein level, which might be controlled at different stages of the enzyme synthesis and processing, e.g. at the translational level, by posttranslational processes such as phosphorylation or binding to chaperone proteins, or by modulation of the rate of protein degradation by proteasomal proteolysis [22]. Similarly in sheep, the pineal Aa-nat mRNA level was found to be only 2-fold higher at night compared with day, while the nocturnal AA-NAT activity was about 7-fold higher, suggesting that translational and/or post-translational processes may also be involved in this regulation [23]. On the other hand, transcriptional regulation appears to play a major role in the rat pineal gland, where the level of nocturnal Aa-nat mRNA was found to be more than 100-fold higher and corresponded to AA-NAT enzymatic activity [24].

In the chicken pineal glands examined here, the amount of Hiomt mRNA was very high at midday, which is out of phase with the Aa-nat transcript (Fig. 2A, B). This pattern seems to be characteristic of the chicken pineal gland, because similar studies performed in the rat detected a nocturnal peak of Hiomt mRNA [25]. The difference between midday and midnight levels of the Hiomt transcript in 2-dayold chickens appeared to be independent of the season of 
hatch, although the number of Hiomt mRNA copies was significantly higher in "summer" chicks (Fig. 2B). Moreover, the quantity of Hiomt mRNA was 20-30 times higher than that of Aa-nat. Despite the significant diurnal/nocturnal difference in Hiomt gene expression in the pineal glands of chickens from both seasons, HIOMT activity did not exhibit similar difference, i.e. it was comparable at both light and dark phase (Fig. 3B). In addition, HIOMT activity was 20-30 times lower than that of AA-NAT. However, it must be stressed that while HIOMT catalyzes the O-methylation of 5 different HO-indole compounds present in the pineal gland (N-acetylserotonin, 5-hydroxytryptophol, 5-hydroxytryptophan, 5-hydroxytryptamine and 5-hydroxy-3-indoleacetic acid) [26], in our experiment, HIOMT activity was assayed using only $\mathrm{N}$-acetylserotonin as the substrate.

The serotonin content of the pineal gland of "winter" chickens did not exhibit diurnal/nocturnal differences, whereas in those hatched in the summer it varied similarly to the expression and activity of AA-NAT (higher in the middle of the dark phase) (Fig. 4B). The elevation of nocturnal levels of 5-HT depends on the expression/activity of tryptophan hydroxylase ( $\mathrm{TrH})$, which transforms tryptophan into 5-hydroxytryptophan (Fig. 1) and fluctuates in a clockdriven circadian rhythm with high values occurring during the night [27]. In addition, exposure to light during the night causes a rapid reduction in nocturnal $\mathrm{TrH}$ activity [28]. The activity of $\mathrm{TrH}$ controls the availability of serotonin; therefore, its plays a very important role in melatonin formation [29]. Serotonin can also be acetylated, although to a lesser extent, by arylamine $\mathrm{N}$-acetyltransferase (A-NAT), which is present in the chick pineal gland and probably contributes to daytime serotonin acetylation, since its activity is stable and does not exhibit cyclical changes [30].

Finally, as the pineal content of the essential substrate tryptophan is very high, regardless of the point of measurement and season (Fig. 4A), this cannot be considered as a factor limiting the level and daily changes of the second measured substrate, serotonin. Diet is the main source of amino acid tryptophan and its administration was found to increase the level and amplitude of both 5-HT and melatonin in the blood of ring doves [31]. On the other hand, nocturnal tryptophan loading of the rat pineal gland led to substantial increases in pineal levels of 5-hydroxytryptophan, 5hydroxyindole acetic acid (5-HIAA) and 5-HT, but resulted in a highly significant reduction in AA-NAT activity. In contrast to other measured indoles, melatonin levels were also found to be significantly diminished by tryptophan loading [32]. In our experiments, the diets of both parental flocks and chicks were the same in winter and summer seasons and adjusted to the period of laying hens' development. It results probably in the same level of tryptophan observed in the pineal gland of 2-day-old chickens of both seasons, indicating, on the other hand, that posttranscriptional processing of Aa-nat mRNA or/and AANAT protein as well as the level of 5-HT may contribute to the season-related changes in pineal biosynthetic activity. This remains in line with our previous data [18] in which AA-NAT activity measured at three nocturnal time-points (ZT13, ZT17 and ZT20) was much higher in "summer" than in "winter" chickens, suggesting that season-related differrences do not consist in the changes in acrophase/rhythm but represent generally elevated chicken pineal activity observed in summer.

The pineal gland, through the secretion of melatonin, is essential for photoperiodic time measurement which allows organisms to anticipate and adapt to changes in environmental conditions [33]. Therefore, the profile of the melatonin rhythm changes with the season [34]. This phenomenon occurs not only in the natural environment but also in the laboratory under different photoperiodic regimens [35]. Furthermore, seasonality in reproduction has been observed in mice kept for several generations in controlled L:D 12:12 conditions [36]. The findings of the present study are in agreement with those obtained in studies of mice, and taken together they clearly suggest the existence of either internal mechanisms capable of recognizing external lighting conditions and/or a kind of "photoperiodic memory", which "remembers" the external lighting conditions experienced by the parental animals or by itself as an embryo. Postnatal circadian organization in the chicken pineal gland may be influenced by embryonic lighting history [37], although it is difficult to determine whether, or explain how, the external lighting conditions experienced by laying hens (kept in artificial photoperiod, 16h Light: $8 \mathrm{~h}$ Darkness, regardless of the season) and by the embryos during incubation (constant darkness) are transmitted to the newly hatched chicks and how this may influence the pineal circadian rhythm in a season-dependent manner. However, the parents, through their own rhythmic behaviour, can influence the microenvironment in which the embryo develops. It was recently proposed that an epigenetic mechanism, such as the maternal age effect, can influence the hormonal content of eggs and the behavioural phenotype of chicks [38]. Therefore, these possible influences have to be taken into consideration when experiments are performed on animals (at least chickens) kept under constant lighting conditions during different external seasons. Moreover, some knowledge about the seasonality of chicken pineal gland activity could be useful for chicken farms or hatcheries, since the melatonin biosynthetic machinery in the pineal gland and the immune function [17] of chickens are season-dependent, even when the birds are kept in controlled artificial lighting conditions.

\section{CONCLUSIONS}

The results of this study suggest the existence of some factors that serve as "external timekeepers" for the chicken embryo, regulating post-transcriptional events affecting two key enzymes that catalyze the final steps of melatonin biosynthesis in the chicken pineal gland. These factors seem to be season-related, and therefore, suggest a maternal influence on the early postnatal pineal gland development in chickens. The possible influence of the natural season on pineal gland function in chickens (and perhaps other species) should be taken into consideration even when experimental animals are kept in controlled laboratory conditions.

\section{ACKNOWLEDGEMENTS}

This work has been performed within the frame of the Polish MSHE grant no. N N303 317733. 


\section{REFERENCES}

[1] Goldman BD. Mammalian photoperiodic system: formal properties and neuroendocrine mechanisms of photoperiodic time measurement. J Biol Rhythms 2001; 16: 283-301.

[2] Herzog ED, Schwartz WJ. A neural clockwork for encoding circadian time. J Appl Physiol 2002; 92: 401-8.

[3] Hazlerigg DG, Wagner GC. Seasonal photoperiodism in vertebrates: from coincidence to amplitude. Trends Endocrinol Metab 2006; 17: 83-91.

[4] Bernard M, Guerlotté J, Grève $\mathrm{P}$, et al. Melatonin synthesis pathway: circadian regulation of the genes encoding the key enzymes in the chicken pineal gland and retina. Reprod Nutr Dev 1999; 39: 325-34.

[5] Arendt J. In: Melatonin and the Mammalian pineal gland. London: Chapman and Hall 1995; pp.11-15.

[6] Malpaux B, Migaud M, Tricoire H, Chemineau P. Biology of mammalian photoperiodism and the critical role of the pineal gland and melatonin. J Biol Rhythms 2001; 16: 336-47.

[7] Iuvone PM, Tosini G, Pozdeyev N, Haque R, Klein DC, Chaurasia SS. Circadian clocks, clock networks, arylalkylamine Nacetyltransferase, and melatonin in the retina. Prog Retin Eye Res 2005; 24: 433-56.

[8] Pandi-Perumal SR, Srinivasan V, Maestroni GJ, Cardinali DP, Poeggeler B, Hardeland R. Melatonin: nature's most versatile biological signal? FEBS J 2006; 273: 2813-38.

[9] Cassone VM. Melatonin's role in vertebrate circadian rhythms. Chronobiol Int 1998; 15: 457-73.

[10] Bailey MJ, Beremand PD, Hammer R, Bell-Pedersen D, Thomas TL, Cassone VM. Transcriptional profiling of the chick pineal gland, a photoreceptive circadian oscillator and pacemaker. Mol Endocrinol 2003; 17: 2084-95.

[11] Zeman M, Gwinner E, Herichova I, Lamosova D, Kost'al L. Perinatal development of circadian melatonin production in domestic chicks. J Pineal Res 1999; 26: 28-34.

[12] Moller M, Moller G. Structural and functional differentiation of the embryonic chick pineal organ in vivo and in vitro. Cell Tissue Res 1990; 260: 337-48.

[13] Zeman M, Gwinner E, Somogyiová E. Development of melatonin rhythm in the pineal gland and eyes of chick embryo. Experientia 1992; 48: 765-8.

[14] Herichova I, Zeman M, Mackova M, Griač P. Rhythms of the pineal $\mathrm{N}$-acetyltransferase mRNA and melatonin concentrations during embryonic and post-embryonic development in chicken. Neurosci Lett 2001; 298:123-6.

[15] Akasaka K, Nasu T, Katayama T, Murakami N. Development of regulation of melatonin release in pineal cells in chick embryos. Brain Res 1995; 692: 283-6.

[16] Csernus VJ, Nagy AD, Faluhelyi N. Development of the rhythmic melatonin secretion in the embryonic chicken pineal gland. Gen Comp Endocrinol 2007; 152: 148-53.

[17] Majewski P, Adamska I, Pawlak J, Barańska A, Skwarło-Sońta K. Seasonality of pineal gland activity and immune functions in chickens. J Pineal Res 2005; 39: 66-72.

[18] Nowak K, Majewski P, Waloch M, Skwarło-Sońta K. Seasonrelated post-embryonic changes in the diurnal rhythm of AA-NAT activity in the chicken pineal gland. Folia Univ Agric Stetin. Zootechnica 2006; 250: 17-24

[19] Chae HD, Park TJ, Lee YK, Lee TG, Kim KT. Rapid and simple measurement of serotonin $\mathrm{N}$-acetyltransferase activity by liquid biphasic diffusion assay. Neurochem Int 1999; 35: 447-51.
[20] Majewski P, Dziwiński T, Pawlak J, Waloch M, Skwarło-Sońta K. Anti-inflammatory and opioid-mediated effects of melatonin on experimental peritonitis in chickens. Life Sci 2005; 76: 1907-20.

[21] Hardeland R. Melatonin, hormone of darkness and more: occurrence, control mechanisms, actions and bioactive metabolites. Cell Mol Life Sci 2008; 65: 2001-18.

[22] Klein DC. Arylalkylamine N-acetyltransferase: "the timezyme". J Biol Chem 2007; 282, 4233-7.

[23] Coon SL, Roseboom PH, Baler R, et al. Pineal serotonin Nacetyltransferase: expression cloning and molecular analysis. Science 1995; 270: 1681-3.

[24] Roseboom PH, Coon SL, Baler R, McCune SK, Weller JL, Klein DC. Melatonin synthesis: analysis of the more than 150 -fold nocturnal increase in serotonin $\mathrm{N}$-acetyltransferase messenger ribonucleic acid in the rat pineal gland. Endocrinology 1996; 137: 3033-45.

[25] Gauer F, Craft CM. Circadian regulation of hydroxyindole-0methyltransferase mRNA levels in rat pineal and retina. Brain Res 1996; 737: 99-109.

[26] Nowak JZ, Szymańska B, Zawilska JB, Białek B. HydroxyindoleO-methyltransferase activity in ocular and brain structures of rabbit and hen. J Pineal Res 1993; 15: 35-42.

[27] Privat K, Ravault JP, Chesneau D, Fevre-Montange M. Day/night variation of tryptophan hydroxylase and serotonin $\mathrm{N}$ acetyltransferase mRNA levels in the ovine pineal gland and retina. J Pineal Res 1999; 26: 193-203.

[28] Florez JC, Takahashi JS. Quantitative two-dimensional ge electrophoretic analysis of clock-controlled proteins in cultured chick pineal cells: circadian regulation of tryptophan hydroxylase. J Biol Rhythms 1996; 11: 241-57.

[29] Thomas KB, Brown AD, Iuvone PM. Elevation of melatonin in chicken retina by 5-hydroxytryptophan: differential light/dark responses. Neuroreport 1998; 9: 4041-4.

[30] Nowak JZ, Zawilska JB, Woldan-Tambor A. Arylamine and arylalkylamine $\mathrm{N}$-acetyltransferases in retina, pineal gland, brain and liver of chicks: a comparative study. Neurochem Int 1995; 27 285-97.

[31] Paredes SD, Terrón MP, Marchena AM, et al. Tryptophan modulates cell viability, phagocytosis and oxidative metabolism in old ringdoves. Basic Clin Pharmacol Toxicol 2007; 101: 56-62.

[32] Reiter RJ. Pineal melatonin: cell biology of its synthesis and of its physiological interactions. Endocr Rev 1991; 12: 151-80.

[33] Lincoln GA. Decoding the nightly melatonin signal through circadian clockwork. Mol Cell Endocrinol 2006; 252: 69-73.

[34] Zawilska JB, Lorenc A, Berezínska M, Vivien-Roels B, Pévet P, Skene DJ. Photoperiod-dependent changes in melatonin synthesis in the Turkey pineal gland and retina. Poult Sci 2007; 86: 1397 405.

[35] Nelson RJ, Drazen DL. Melatonin mediates seasonal changes in immune function. Ann N Y Acad Sci 2000; 917: 404-15.

[36] Drickamer LC. Seasonal variation in fertility, fecundity and litter sex ratio in laboratory and wild stocks of house mice (Mus domesticus). Lab Anim Sci 1990; 40: 284-8.

[37] Nichelmann M, Hochel J, Tzschentke B. Biological rhythms in birds-development, insights and perspectives. Comp Biochem Physiol Mol Integr Physiol 1999; 124: 429-37.

[38] Formanek L, Richard-Yris MA, Houdelier C, Lumineau S. Epigenetic maternal effects on endogenous rhythms in precocial birds. Chronobiol Int 2009; 26: 396-414.

This is an open access article licensed under the terms of the Creative Commons Attribution Non-Commercial License (http://creativecommons.org/licenses/by$\mathrm{nc} / 3.0 /$ ), which permits unrestricted, non-commercial use, distribution and reproduction in any medium, provided the work is properly cited 